\title{
Concentrations of nutrients in mouse oviduct fluid and their effects on embryo development and metabolism in vitro*
}

\author{
D. K. Gardner† and H. J. Leese \\ Biology Department, University of York, Heslington, York YO1 5DD, UK
}

\begin{abstract}
Summary. An ultramicrofluorometric technique was used to analyse the nutrient composition of mouse oviduct fluid. The concentrations of pyruvate, glucose and lactate in the vicinity of the cumulus mass were $0.37,3.40$ and $4.79 \mathrm{~mm}$ respectively. In the absence of cumulus cells, the concentration of pyruvate was significantly reduced, to $0.14 \mathrm{~mm}$, while the concentration of glucose was significantly increased to $5.19 \mathrm{~mm}$. Glutamine, which may help to overcome the '2-cell block' in mouse embryos in culture, was present at a concentration of $0.20 \mathrm{~mm}$.

A modified medium (MTF) in which the concentration of nutrients was similar to that in mouse oviduct fluid was prepared and its effects on embryo development and metabolism in vitro were compared with that of a conventional embryo culture medium (M16). The percentage of zygotes forming blastocysts in vitro by Day 5 was similar in both media ( $82 \%$ in M16, 79\% in MTF). Rates of development, as assessed by cell number, were also comparable. However, the proportion of glucose consumed which was converted to lactate increased dramatically following culture; from $44 \%$ in fresh blastocysts, to $73 \%$ and $91 \%$ in blastocysts derived from 8-cell embryos cultured for $24 \mathrm{~h}$ in media MTF and M16 respectively.
\end{abstract}

Keyw'ords: oviduct fluid; mouse; nutrients; culture; metabolism; embryo

\section{Introduction}

Although considerable progress has been made in culturing preimplantation mammalian embryos, it is only in a few species that complete development from the zygote to blastocyst may be achieved in culture (Biggers, 1987). Even in such species, embryo development in vitro is retarded by 18-24 h compared with that in vivo (Bowman \& McLaren, 1970; Harlow \& Quinn, 1982). The reasons for these difficulties remain to be resolved.

It is reasonable to suppose that the composition of embryo culture media should reflect the concentration of nutrients, electrolytes and macromolecules present in the lumen of the female reproductive tract. The electrolyte and nutrient composition of oviduct fluid is known for several species, such as the rabbit and large domestic animals (Leese, 1988). Although the electrolyte composition of the mouse oviduct has been determined using an electron probe microanalyser (Borland et al., 1977), there are no reports on the concentrations of nutrients in the mouse oviduct lumen due to the very small volumes of fluid present and the insensitivity of the available analytical techniques.

\footnotetext{
${ }^{*}$ Reprint requests to $\mathrm{Dr} \mathbf{H}$. J. Leese.

†Present address: Centre for Early Human Development, Monash Medical Centre, 246 Clayton Road, Melbourne, Victoria 3168, Australia.
} 
An ultramicrofluorometric technique has been developed to assay metabolite levels in nanolitre samples of biological fluids (Leese \& Barton, 1984) and in the present study this technique has been used to measure the amounts of pyruvate, glucose, lactate, glutamine, glutamate and total protein in mouse oviduct fluid. Pyruvate, glucose and lactate are the principal energy substrates added to embryo culture medium, not only for the mouse but for domestic species and the human. Glutamine has been shown to support oocyte maturation in the rabbit (Bae \& Foote, 1975), and to have a beneficial effect on the development of 8-cell hamster embryos in vitro (Carney \& Bavister, 1987). Chatot et al. (1989) have shown that glutamine can help overcome the '2-cell block' in mouse embryos in culture.

On the basis of the measurements of nutrients in the mouse oviduct lumen, a modified embryo culture medium was formulated and its effect on embryo development and metabolism in vitro determined.

\title{
Materials and Methods
}

\section{Collection of oviduct fluid}

Oviduct fluid was collected from F1 (CBA/Ca $\times$ C57BL/6) hybrid female mice. Virgin females (6 weeks of age) were induced to ovulate with 5 i.u. PMSG (Folligon: Intervet, Cambridge, UK) administered at 12:00 h, followed $48 \mathrm{~h}$ later by 5 i.u. hCG (Chorulon; Intervet). At $21 \mathrm{~h}$ after hCG, the oviducts were dissected free of other tissues, rinsed thoroughly in $0.9 \%(\mathrm{w} / \mathrm{v}) \mathrm{NaCl}$, blotted dry on Whatman No. 4 filter paper and placed under mineral oil (Sigma, St Louis, MO, USA). The ampulla of the oviduct is distended with fluid after ovulation in the region of the cumulus mass. This fluid was collected using fine-tipped pipettes made as follows: $75 \mathrm{~mm} \times 1 \mathrm{~mm}$ bore capillary tubing (Bilbate) was drawn out to a fine point on a pipette puller (tip diameter $30-40 \mu \mathrm{m}$ ). The pipettes were siliconized with $2 \%(\mathrm{v} / \mathrm{v})$ dimethyldichlorosilane solution and the tips loaded with mineral oil. Oviduct fluid uptake and expulsion were controlled by means of an air-filled syringe attached to the pipette by plastic tubing. The wall of the distended ampulla was pierced and a sample of clear fluid $(\sim 20 \mathrm{nl})$ taken up under suction. The fluid was then expelled onto a siliconized microscope slide under mineral oil and its contents analysed immediately. Attempts were made to collect neat oviduct fluid samples on Days 2 and 3 of pregnancy, and from the uterine lumen, but without success.

To determine the contribution made by the cumulus mass to the levels of nutrients in the oviduct, luminal fluid was sampled from unilaterally ovariectomized mice. Fluid secretion in the oviducts of such females is under the control of the remaining ovary. This results in one oviduct having a distended ampulla but lacking a cumulus mass. The mice were allowed to recover for 4 weeks after ovariectomy before oviduct fluid was sampled. Any local effect of the ovary would therefore be absent in the oviduct adjoining the site of ovariectomy.

\section{Analysis of oviduct fluid}

Samples of oviduct fluid were analysed for nutrients and amino acids using an ultramicrofluorometric technique (Leese et al., 1984). This is a miniaturized version of the conventional methods of enzymic analysis in which the pyridine nucleotides NADH or NADPH are generated or consumed in coupled reactions (Lowry \& Passonneau, 1972; Bergmeyer \& Gawehn, 1974). Instead of being carried out in cuvettes, the assays were performed in nanolitresized droplets on siliconized microscope slides under mineral oil, previously saturated for $24 \mathrm{~h}$ with $0.9 \%(\mathrm{w} / \mathrm{v}) \mathrm{NaCl}$. Specially constructed micropipettes, capable of delivering volumes in the nano- and picolitre range and constructed on a microforge, were used to pipette the samples of fluid and reagents. The fluorescence of the reactions was quantified by using a fluorescence microscope (Leitz Diavert), with photomultiplier and digital photometer attachments. Fluorescence was linear with respect to concentration over the range studied. The assays were based on the reactions described below.

\section{Pyruvate assay and reagents}

$$
\begin{aligned}
& \mathrm{LDH} \\
& \text { Pyruvate }+\mathrm{NADH}+\mathrm{H}^{+}<==>\text {lactate }+\mathrm{NAD}^{+}
\end{aligned}
$$

Reagents: $0.075 \mathrm{~mm}-\mathrm{NADH}, 28 \mathrm{U}$ lactate dehydrogenase/ml (EC 1.1.1.27), in EPPS buffer (4-(2-hydroxyethyl)-1piperazine propane-sulphonic acid), $\mathrm{pH} 8 \cdot 0$.

\section{Glucose assay and reagents}

\author{
Hexokinase \\ Glucose + ATP - - - > glucose-6-phosphate + ADP \\ G6PDH \\ Glucose-6-phosphate $+\mathrm{NADP}^{+}<>$6-phosphogluconate + NADPH $+\mathrm{H}^{+}$
}


Reagents: $3.7 \mathrm{~mm}-\mathrm{MgSO}_{4} .7 \mathrm{H}_{2} \mathrm{O}, 0.6 \mathrm{~mm}-\mathrm{NADP}+, 0.5 \mathrm{~mm}$-ATP, $0.5 \mathrm{~mm}$-dithiothreitol, $12 \mathrm{U}$ hexokinase $/ \mathrm{ml}$ (EC 2.7.1.I), $6 \mathrm{U}$ glucose 6-phosphate dehydrogenase/ml (EC 1.1.1.49), in EPPS buffer, pH 8.0.

Lactate assay and reagents

$$
\text { Lactate }+\mathrm{NAD}^{+}<==>\text {pyruvate }+\mathrm{NADH}+\mathrm{H}^{+}
$$

Reagents: $4.76 \mathrm{~mm}-\mathrm{NAD}^{+}, 100 \mathrm{U}$ lactate dehydrogenase $/ \mathrm{ml}, 2.6 \mathrm{~mm}$-EDTA, in glycine-hydrazine buffer, pH 9.4 .

Glutamine assay and reagents

$$
\begin{gathered}
\text { Glutaminase } \\
\text { Glutamine }+\mathrm{H}_{2} \mathrm{O}--->\text { glutamate }+\mathrm{NH}_{3}
\end{gathered}
$$

Reagents: $50 \mathrm{U}$ glutaminase/ml (EC 3.5.1.2), in acetate buffer, $\mathrm{pH} 5.0$.

\section{Glutamate assay and reagents}

$$
\begin{gathered}
\text { GDH } \\
\text { Glutamate }+\mathrm{H}_{2} \mathrm{O}+\mathrm{NAD}^{+}<-->2 \text {-oxoglutarate }+\mathrm{NH}_{4}{ }^{+}+\mathrm{NADH}
\end{gathered}
$$

Reagents: $1.6 \mathrm{~mm}$-NAD, 1.0 mM-ADP, $100 \mathrm{U}$ glutamate dehydrogenase/ml (EC 1.4.1.3), in glycine-hydrazine buffer, $\mathrm{pH} 9 \cdot 0$

Unlike the two steps of the glucose assay (2) which can take place in one microdrop, the glutamine assay had to be carried out in two separate microdrops, since each step of the assay has a different $\mathrm{pH}$ optimum. When the glutamate assays were carried out (reaction 5), there was a constant generation of NADH from NAD ${ }^{+}$. To overcome this problem, the analysis for glutamate was performed in the presence and absence of glutamate dehydrogenase; any difference between the two treatments was due to the presence of glutamate in the fluid. By subtracting the two values, it was found that the glutamate dehydrogenase reaction went to completion in $3 \mathrm{~min}$.

Dehydrogenase activity. Lactate dehydrogenase is present in the lumen of the mouse oviduct (Gibson \& Masters, 1970). The assay conditions for reaction (5) are very similar to those for reaction (3), and hence for lactate dehydrogenase. Furthermore, lactate is present in the oviduct fluid samples. To determine whether the constant generation of NADH referred to above was due to LDH activity, the assay was performed in the absence of hydrazine (used to trap pyruvate as pyruvate hydrazone). The reagents used were: $1.6 \mathrm{~mm}-\mathrm{NAD}^{+}, 10 \mathrm{~mm}-$ pyruvate, in glycine buffer, pH $9 \cdot 0$. Under these conditions, there was no generation of NADH, suggesting that the non-specific creep was due to LDH. The activity of LDH measured in this way was therefore determined by linear regression, and expressed as pmol $\mathrm{NADH} / \mathrm{h} / \mathrm{mg}$ protein.

Protein assay and reagents. Based on the methods of Zawieja et al. (1984), $80 \mathrm{mg} o$-phthalaldehyde (in $1.0 \mathrm{ml}$ ethanol) were added to $100 \mathrm{ml} 0.4 \mathrm{M}$-boric acid buffer, $\mathrm{pH} 9 \cdot 7$. Then $30 \mathrm{ml}$ of a $30 \%$ Brij solution were added, and the solution filtered through a $0 \cdot 22 \mu \mathrm{m}$ filter (Gelman). Mercaptoethanol was added $(5 \mu \mathrm{l} / \mathrm{ml}) 1 \mathrm{~h}$ before the assay. Bovine serum albumin in $0.9 \%(\mathrm{w} / \mathrm{v}) \mathrm{NaCl}$ was used as the protein standard.

\section{Embryo culture and cell counts}

A modified medium (referred to as MTF; Mouse Tubal Fluid) based on Medium M16 (Whittingham, 1971) was prepared but using concentrations of pyruvate $(0.37 \mathrm{~mm})$, glucose $(3.40 \mathrm{~mm})$ and lactate $(4.79 \mathrm{~mm})$ similar to those present in mouse oviduct fluid. The osmolarity of the modified medium (288-292 mosmol) was preserved by altering the sodium chloride concentration.

Virgin Fl females ( 6 weeks of age) were induced to ovulate (as above) and placed with F1 males. The presence of a vaginal plug the following morning indicated that mating had occurred. At $21 \mathrm{~h}$ after hCG injection, embryos were teased from the oviduct into Medium M2 (Quinn et al., 1982). The cumulus cells were removed with hyaluronidase, $1 \mathrm{mg} / \mathrm{ml}$ (Bovine Testes, Sigma), in Medium M2. Embryos from different females were pooled, checked for the presence of a second polar body and then assigned randomly to one of the media. Embryos were cultured in groups of 10 in approximately $20 \mu \mathrm{l}$ medium, under $3 \mathrm{ml}$ paraffin oil in Falcon dishes, in an atmosphere of $5 \%\left(\mathrm{CO}_{2}\right)$ in air.

On Day 5 after hCG, the number of embryos reaching the blastocyst stage was recorded. Several blastocysts from each treatment were then selected at random for cell counting. Blastocysts were fixed by the air-drying technique of Tarkowski (1966), and the blastomeres stained with toluidine blue in citrate buffer ( $\mathrm{pH} \mathrm{4.4).} \mathrm{Cell} \mathrm{counts} \mathrm{were} \mathrm{checked}$ independently by a second observer.

Batches of culture stocks were made up on 3 separate occasions in an attempt to eliminate variation when preparing media. This enabled an analysis of variance to be performed within and between treatments.

\section{Assessment of embryo metabolism}

The metabolism of single blastocysts was determined using the method of Gardner \& Leese (1986). Embryos at the 8 -cell stage were collected $69 \mathrm{~h}$ after hCG and cultured in Medium M16 or MTF. After $24 \mathrm{~h}$, the size of the resultant 
blastocysts was measured. Only blastocysts with a diameter of $94-96 \mu \mathrm{m}$ were used for metabolic assessment to eliminate differences in nutrient uptake due to size. Non-cultured control blastocysts were flushed from the uterus at $93 \mathrm{~h}$ after hCG, and also selected for metabolic assessment on a size basis.

All embryos were washed 3 times in substrate-free Medium M2, and twice in Medium M2 containing $1 \mathrm{mm-}$ glucose as the sole energy source. The blastocysts were then transferred individually to $30 \mathrm{nl}$ drops of Medium M2, containing $1 \mathrm{~mm}$-glucose, on siliconized slides under saline-saturated mineral oil and incubated at $37^{\circ} \mathrm{C}$ for $3 \mathrm{~h}$. Serial $\mathrm{I} \mathrm{nl}$ samples of medium were taken every $20 \mathrm{~min}$ and assayed for glucose and lactate as described above.

\section{Results}

The levels of nutrients, total protein and the activity of LDH in luminal fluid from the ampulla of the mouse oviduct are shown in Table 1.

Table 1. Analyses of selected constituents of mouse oviduct fluid

\begin{tabular}{|c|c|c|}
\hline Component & Cumulus present & Cumulus absent \\
\hline Pyruvate (mM) & $0.37 \pm 0.03(25)$ & $0.14 \pm 0.02^{* *}(5)$ \\
\hline Glucose (mM) & $3.40 \pm 0.14(18)$ & $5 \cdot 19 \pm 0 \cdot 20^{*}$ \\
\hline Lactate (mM) & $4.79 \pm 0.32(25)$ & $4 \cdot 26 \pm 0.23$ \\
\hline Glutamine (mM) & $0.20 \pm 0.04$ & n.d. \\
\hline Glutamate (mM) & $0.47 \pm 0.11$ & n.d. \\
\hline Protein $(\mathrm{mg} / \mathrm{ml})$ & $10 \cdot 90 \pm 1.90$ & n.d. \\
\hline $\begin{array}{l}\text { Lactate dehydrogenase } \\
\text { (pmol NADH/h/mg protein) }\end{array}$ & $9.94 \pm 2.29$ & n.d. \\
\hline
\end{tabular}

Values are mean \pm s.e.m. (no. of mice).

Significant effect of cumulus, ${ }^{*} P<0.05,{ }^{*} P<0.01$.

n.d. Not determined.

In the absence of a cumulus mass, the concentration of pyruvate in the fluid was significantly reduced $(P<0.01)$, while that of glucose was significantly increased $(P<0.05)$. The concentration of lactate was not affected by the absence of a cumulus mass.

The ability of mouse embryos to develop in vitro in the presence of physiological concentrations of metabolites is shown in Table 2. Analysis of variance revealed no differences within treatments. There was no difference in the ability of either medium to support embryo development.

Table 2. Development of 1-cell mouse embryos cultured for 5 days in Medium M16 or MTF

\begin{tabular}{lccc}
\hline & & \multicolumn{2}{c}{ Cell no. } \\
Medium & $\begin{array}{c}\text { \% Development } \\
\text { to blastocyst }\end{array}$ & Mean \pm s.e.m. & Range \\
\cline { 3 - 4 } M16 & $82 \cdot 2(500)$ & $44 \cdot 8 \pm 0.68(90)$ & $28-61$ \\
MTF & $78.6(500)$ & $46.4 \pm 0.81(96)$ & $31-80$ \\
\hline
\end{tabular}

No. of embryos are in parentheses.

The effects of $24 \mathrm{~h}$ in culture on embryo metabolism are shown in Table 3. The uptake of glucose by cultured blastocysts was not different from that of blastocysts flushed directly from the uterus. However, lactate production was significantly increased $(P<0.01)$ after culture in both media, with Medium M16 having the greater effect. The percentage of glucose metabolized by glycolysis was calculated on the basis that 1 mol glucose formed 2 mol lactate. Whereas fresh blastocysts converted $44 \%$ of the glucose consumed to lactate, the values for blastocysts derived from culture in Media M16 and MTF were $91 \%$ and $73 \%$ respectively. 
Table 3. The uptake of $1 \mathrm{~mm}$-glucose and lactate production by single mouse blastocysts

\begin{tabular}{|c|c|c|c|}
\hline Medium & $\begin{array}{l}\text { Glucose uptake } \\
(\mathrm{pmol} / \mathrm{embryo} / \mathrm{h})\end{array}$ & $\begin{array}{l}\text { Lactate production } \\
(\mathrm{pmol} / \mathrm{embryo} / \mathrm{h})\end{array}$ & $\begin{array}{l}\% \text { Glucose } \\
\text { to lactate }\end{array}$ \\
\hline M16 & $4 \cdot 32 \pm 0 \cdot 19(15)$ & $7 \cdot 85 \pm 0.56^{* *}+(15)$ & 91 \\
\hline MTF & $4.09 \pm 0.21(15)$ & $5.94 \pm 0.42^{* *}$ & 73 \\
\hline Control & $4.06 \pm 0.27(15)$ & $3.61 \pm 0.35$ & 44 \\
\hline
\end{tabular}

Values are mean \pm s.e.m. (no. of embryos)

**Significantly different from control $(P<0.01)$.

$\uparrow$ Significantly different from value for Medium MTF $(P<0 \cdot 01)$.

\section{Discussion}

We have shown that the concentrations of nutrients in small (10-20 nl) samples of biological fluids may readily be determined using ultramicrofluorometric techniques of analysis. The time from removal of the oviduct from the animal to sampling the luminal fluid was of the order of 2 min, and we are confident that the concentrations of nutrients measured reflect physiological levels. Previous investigations into the composition of oviduct fluid of larger animals, such as the rabbit and sheep, relied on the chronic collection of the fluid, over a period of several hours or days, from cannulated oviducts (Brackett \& Mastroianni, 1974). Nieder \& Corder (1983) examined the amounts of pyruvate and lactate in whole sections of mouse oviducts using histochemical techniques. However, there was no analysis of luminal contents, nor any attempt to distinguish the concentrations in the endosalpinx from those in the myosalpinx.

The concentrations of pyruvate and glucose in mouse oviduct fluid are similar to those found in most embryo culture medium (0.25-0.5 mm-pyruvate and $5.56 \mathrm{~mm}$-glucose). However, the physiological concentration of lactate $(4 \cdot 79 \mathrm{~mm})$ differs markedly from the $25-30 \mathrm{~mm}$ value routinely used for embryo culture. The concentrations of pyruvate and lactate in most embryo culture media derive from work by Brinster (1965a, b), who used factorial experiments to determine the optimal level of nutrients which supported the development of 2-cell mouse embryos to blastocysts in culture. The concentration of glucose $(5.56 \mathrm{~mm})$ was chosen to mimic plasma levels. Wales \& Whittingham (1973) repeated Brinster's (1965a, b) studies, and found that the concentrations of pyruvate and lactate which best supported development of the 2-cell embryo were $0.3-0.4 \mathrm{~mm}$ and $4.0 \mathrm{~mm}$ respectively. No reasons were given for the discrepancy between the two studies, but the concentration of lactate in most embryo culture media has remained at the high level used by Brinster $(1965 \mathrm{a}, \mathrm{b})$. The nutrient composition of rabbit oviduct fluid collected at oestrus $(0.30 \mathrm{M}$ pyruvate, $1.46 \mathrm{~mm}$-glucose, $3.67 \mathrm{~mm}$-lactate) is very similar to that of the mouse (Leese \& Barton, 1985).

When mouse oviduct fluid was sampled from a distended ampulla lacking a cumulus mass, i.e. from unilaterally ovariectomized animals, the concentrations of pyruvate and glucose differed significantly from those obtained when the cumulus mass was present (Table 1). The reduced concentration of pyruvate in the absence of cumulus cells strongly suggests that these cells are partly responsible for maintaining the concentration of pyruvate in oviduct fluid. Although it is possible that the absence of local hormonal stimulation after ovariectomy contributed to the reduced levels of pyruvate observed, Donahue \& Stern (1968) demonstrated that follicle cells are capable of releasing pyruvate into the surrounding medium when incubated with glucose. This finding was confirmed by Leese \& Barton (1985), who showed that both whole cumulus masses and isolated cumulus cells readily form pyruvate from glucose and/or lactate in vitro. Ahuja (1988) has also reported the formation of pyruvate by human cumulus cells. Since the concentration of glucose in oviduct fluid is significantly lower in the presence of a cumulus mass, it is possible that cumulus cells 
in vivo utilize glucose preferentially to form pyruvate. We therefore believe that the balance of the evidence favours the view that the cumulus cells ovulated with the oocyte also contribute to the levels of nutrients in the oviduct and may therefore have a direct effect on early embryo development.

The detection of glutamine in mouse oviduct fluid is of particular significance, in view of recent interest in the role of this amino acid in preimplantation embryo development in vitro. Miller \& Schultz (1987) collected samples of rabbit oviduct and uterine fluids for amino acid analysis by h.p.l.c. Unfortunately, the glutamine-asparagine peak was poorly resolved. However, it was estimated that the combined values of glutamine and asparagine in the uterus on Day 1 and Day 3 of pregnancy were about $0.37 \mathrm{~mm}$ and $0.58 \mathrm{~mm}$ respectively. The concentration of glutamine in the mouse oviduct, $0.20 \mathrm{~mm}$, is in line with these estimates. Chatot et al. (1989) have provided evidence that the presence of glutamine in embryo culture media can help to overcome the 2-cell block in mice. Gardner et al. (1989) have demonstrated that the uptake of glutamine by single preimplantation mouse embryos increases with development, and that the uptake of this amino acid is affected by other energy sources during the first 2 days of development. The interaction of glutamine with other energy sources in other cell types has been well documented (Morgan \& Faik, 1981).

The concentration of total protein measured in mouse oviduct fluid $(10.9 \mathrm{mg} / \mathrm{ml})$ is very similar to that for the rat $(\sim 9 \mathrm{mg} / \mathrm{ml}$ : Shalgi et al., 1977), rabbit $(8 \mathrm{mg} / \mathrm{ml}$ : Iritani et al., 1971) and sheep $(\sim 12 \mathrm{mg} / \mathrm{ml}$ (Restall \& Wales, 1966). Our value for the mouse is about twice the concentration of protein used in most embryo culture media.

In this study the activity of LDH was measured by the rate of conversion of lactate to pyruvate, although normally LDH activity is measured by its rate of conversion of pyruvate to lactate. This means that it is difficult to compare the activity of $\mathbf{L D H}$ in mouse oviduct fluid with that of other tissues (Buhl \& Jackson, 1978). The physiological role of luminal LDH is unknown, because there is little if any free NAD(H) in the oviduct (Leese \& Aldridge, 1979).

Results from the embryo culture experiments (Table 2) revealed no differences in the ability of the two media, M16 and MTF, to support zygote development, either in terms of blastocoele formation or cell number. The values of blastocyst cell number (Table 2) are the same as those obtained by Harlow \& Quinn (1982) $(44.0 \pm 1.80)$ for $(\mathrm{CBA} / \mathrm{Ca} \times \mathrm{C} 57 \mathrm{BL} / 6)$-derived embryos, cultured from Day 2 to Day 5. The main difference between Media M16 and MTF is in the concentration of lactate ( 23.3 and $4.79 \mathrm{~mm}$ respectively). That the two media did not differ in their ability to support embryo development calls into question the rationale for having such high levels of lactate in Medium M16 and other embryo culture media. In some in-vitro fertilization clinics, the same medium, containing a high concentration of lactate, is used for oocyte maturation, sperm capacitation and embryo culture. Evidence is emerging that a high lactate concentration in the medium is in fact inhibitory to sperm capacitation (Neill \& Olds-Clarke, 1988).

Gardner \& Leese (1988) have previously shown that single mouse embryos produce considerable quantities of lactate by aerobic glycolysis. The percentage of glucose converted to lactate by the mouse embryo increased as development proceeded (25\% at the 2 -cell stage, $40 \%$ at the blastocyst stage). The most striking feature of the results was the increase, after overnight culture, in the proportion of glucose consumed which could be accounted for by lactate formation. High levels of aerobic glycolysis have long been known to be a feature of cells in culture, being first reported by Warburg (1926). The phenomenon is well-illustrated in cultured hepatocytes, which over a period of hours in culture switch their metabolism from one of lactate consumption to lactate production (Gebhardt et al., 1978). The reasons for this metabolic switch are obscure, but would appear to relate to the cells' incapacity to continue to generate ATP at a sufficient rate by oxidative phosphorylation, leaving aerobic glycolysis as the only alternative. The implication is that the high levels of lactate output are an artefact of embryo culture. Indeed, Menke \& McLaren (1970) showed that blastocysts derived from cultured 8-cell embryos produced significantly less $\mathrm{CO}_{2}$ from pyruvate and lactate than did freshly collected uterine blastocysts, inferring that oxidative phosphorylation was inhibited. However, mouse embryos cultured in the more physiological 
medium, MTF, produced significantly less lactate than those in Medium M16 (Table 3) and it is possible that the more physiological concentrations of nutrients are less detrimental to the developing embryo.

It is hoped that a knowledge of the composition of the fluids in the female reproductive tract will enable embryo culture media to be designed on a more physiological basis. Tervit et al. (1972) formulated a medium based on the electrolyte, lactate and glucose levels in sheep oviduct, as measured by Restall \& Wales (1966), and obtained better development of both sheep and cattle embryos in this medium. Similarly, Quinn et al. (1985) used the ionic constitution of human oviduct fluid (Lippes et al., 1972) as the basis of a modified medium. Although an improvement in pregnancy rates over conventional medium was obtained, this was not confirmed by Cummins et al. (1986). In our work no improvement in embryo development was observed using physiological levels of nutrients but there was a marked effect on embryo metabolism.

Placing embryos in culture imposes an artificial stress on them. For example, the presence of glucose is inhibitory to early hamster embryos (Schini \& Bavister, 1988), and possibly those of the mouse (Chatot et al., 1989), although it is probable that glucose is present in the lumen of the hamster oviduct, as it is in the mouse, rabbit and human. It is possible that the optimal conditions for embryo development in vitro need not necessarily reflect the environment in vivo. Indeed, Leese (1989) has suggested that high concentrations of lactate in embryo culture media may help overcome the tendency of embryos to generate ATP by glycolysis and force them to use mitochondrial respiration.

During preimplantational development, the mammalian embryo is exposed to a continually changing environment as it passes along the female tract. Embryo requirements for nutrients change during development (Leese \& Barton, 1984; Gardner \& Leese, 1986), switching from a pyruvate- to a glucose-based metabolism around the time of compaction and entry into the uterus. It would seem likely that the optimal development of embryos in vitro could well occur in not one but possibly two or more media, each one reflecting the embryos' requirements as development proceeds.

We thank Amanda Gott for expert assistance and Dr Anne McLaren for helpful suggestions on the collection of oviduct fluid. Financial support from "Birthright" is gratefully acknowledged.

\section{References}

Ahuja, K.K. (1988) Fertilization: the importance of scientific research to clinical practice. Br.J. Family Planning 13, 18-24.

Bae, I-H. \& Foote, R.H. (1975) Carbohydrate and amino acid requirements and ammonia production of rabbit follicular oocytes matured in vitro. Expl Cell Res. 91, $113-118$.

Bergmeyer, H.U. \& Gawehn, K. (1974) Methods of Enzymatic Analysis, 2nd edn. Academic Press, New York.

Biggers, J.D. (1987) Pioneering mammalian embryo culture. In The Mammalian Preimplantation Embryo, pp. 1-22. Ed. B. D. Bavister. Plenum Press, New York.

Borland, R.M., Hazra, S., Biggers, J.D. \& Lechene, C.P. (1977) The elemental compositon of the environment of the gametes and preimplantation embryo during the initiation of pregnancy. Biol. Reprod. 16, 147-157.

Bowman, P. \& McLaren, A. (1970) Cleavage rate of mouse embryos in vivo and in vitro. J. Embryol. exp. Morph. 24, 203-207.

Brackett, B.G. \& Mastroianni, L., Jr (1974) Composition of oviductal fluid. In The Oviduct and its Functions, pp. 133-150. Eds A. D. Johnson \& C. W. Foley. Academic Press, New York.

Brinster, R.L. (1965a) Studies on the development of mouse embryos in vitro II. The effect of energy sources. J. exp. Zool. 158, 59-68.

Brinster, R.L. (1965b) Studies on the development of mouse embryos in vitro IV. Interaction of energy sources. J. Reprod. Fert. 10, 227-240.

Buhl, S.N. \& Jackson, K.Y. (1978) Optimal conditions and comparison of lactate dehydrogenase catalysis of the lactate-to-pyruvate and pyruvate-to-lactate reactions in human serum at 25,30 and $37^{\circ} \mathrm{C}$. Clin. Chem. 24, 828-831.

Carney, E.W. \& Bavister, B.D. (1987) Stimulatory and inhibitory effects of amino acids on the development of hamster eight-cell embryos in vitro. $J$. in Vitro Fert. Embryo Transfer 4, 162-167.

Chatot, C.L., Ziomek, C.A., Bavister, B.D., Lewis, J.L. \& Torres, I. (1989) An improved culture medium supports development of random-bred 1-cell mouse embryos in vitro. J. Reprod. Fert. 86, 679-688. 
Cummins, J.M., Breen, T.M., Fuller, S.M., Harrison, K.L., Shaw, J.M., Wilson, L.M. \& Hennessey, J.F. (1986) Comparison of two media in a human in vitro fertilization program. J. in Vitro Fert. Embryo Transfer 3, 326-330.

Donahue, R.P. \& Stern, S. (1968) Follicular cell support of oocyte maturation: production of pyruvate in vitro. J. Reprod. Fert. 17, 395-398.

Gardner, D.K. \& Leese, H.J. (1986) Noninvasive measurement of nutrient uptake by single cultured preimplantation mouse embryos. Human Reprod. 1, 25-27.

Gardner, D.K. \& Leese, H.J. (1988) The role of glucose and pyruvate transport in regulating nutrient utilization by preimplantation mouse embryos. Development 104, 423-429.

Gardner, D.K., Clarke, R.N., Lechene, C.P. \& Biggers, J.D. (1989) Development of a noninvasive ultramicrofluorometric method for measuring net uptake of glutamine by single preimplantation mouse embryos. Gamete Res. (In press).

Gebhardt, R., Bellemann, P.\& Mecke, D. (1978) Metabolic and enzymatic characteristics of adult rat liver parenchymal cells in non-proliferating primary monolayer cuitures. Expl Cell Res. 112, 431-441.

Gibson, C. \& Masters, C.J. (1970) Oviductal lactate dehydrogenase. J. Reprod. Fert. 22, 157-159.

Harlow, G.M. \& Quinn, P. (1982) Development of preimplantation mouse embryos in vivo and in vitro. Aust. J. biol. Sci. 35, 187-193.

Iritani, A., Nishikawa, Y., Gomes, W.R. \& VanDemark, N.L. (1971) Secretion rates and chemical composition of oviduct and uterine fluids in rabbits. $J$. Anim. Sci. 33, 829--835.

Leese, H.J. (1988) The formation and function of oviduct fluid. J. Reprod. Fert. 82, 843-856.

Leese, H.J. (1989) Energy metabolism of the preimplantation embryo. In Early Embryo Development and Paracrine Relationships, (in press). Eds S. Heyner \& L. Wiley. Alan R. Liss, New York.

Leese, H.J. \& Aldridge, S. (1979) The movement of pyruvate, lactate and lactate dehydrogenase into rabbit oviductal fluid. J. Reprod. Fert. 56, 619-622.

Leese, H.J. \& Barton, A.M. (1984) Pyruvate and glucose uptake by mouse ova and preimplantation embryos. J. Reprod. Fert. 72, 9-13.

Leese, H.J. \& Barton, A.M. (1985) Production of pyruvate by isolated mouse cumulus cells. J. exp. Zool. 234, 231-236.

Leese, H.J., Biggers, J.D., Mroz, E.A. \& Lechene, C. (1984) Nucleotides in a single mammalian ovum or preimplantation embryo. Analyt. Biochem. 140, $443-448$.

Lippes, J., Enders, R.G., Pragay, D.A. \& Bartholomew, W.R. (1972) The collection and analysis of human fallopian tubal fluid. Contraception 5, 85-103.
Lowry, O.H. \& Passonneau, J.V. (1972) A Flexible System of Enzymatic Analysis. Academic Press, New York.

Menke, T.M. \& McLaren, A. (1970) Mouse blastocysts grown in vivo and in vitro: carbon dioxide production and trophoblast outgrowth. J. Reprod. Fert. 23, $117-127$.

Miller, J.G.O. \& Schultz, G.A. (1987) Amino acid content of preimplantation rabbit embryos and fluids of the reproductive tract. Biol. Reprod. 36, 125-129.

Morgan, M.J. \& Faik, P. (1981) Carbohydrate metabolism in cultured animal cells. Bioscience Reports 1, 669-686.

Neill, J.M. \& Olds-Clarke, P. (1988) Incubation of mouse sperm with high lactate delays capacitation and hyperactivation and lowers fertilization levels in vitro. Gamete Res. 20, 459473.

Nieder, G.L. \& Corder, C.N. (1983) Pyruvate and lactate levels in oviducts of cycling, pregnant and pseudopregnant mice. Biol. Reprod. 28, 566-574.

Quinn, P., Barros, C. \& Whittingham, D.G. (1982) Preservation of hamster oocytes to assay the fertilizing capacity of human spermatozoa. J. Reprod. Fert. 66, 161-168.

Quinn, P., Kerin, J.F. \& Warnes, G.M. (1985) Improved pregnancy rate in human in vitro fertilization with the use of a medium based on the composition of human tubal fluid. Fert. Steril. 44, 493-498.

Restall, B.J. \& Wales, R.G. (1986) The fallopian tube of the sheep. III. The chemical composition of the fluid from the fallopian tube. Aust. J. biol. Sci. 19, $687-698$.

Schini, S.A. \& Bavister, B.D. (1988) Two-cell block to development of cultured hamster embryos is caused by phosphate and glucose. Biol. Reprod. 39, 1183-1192.

Shalgi, R., Kaplan, R. \& Kraicer, P.F. (1977) Proteins of follicular, bursal and ampullar fluids of rats. Biol. Reprod. 17, 333-338.

Tarkowski, A.K. (1966) An air-drying method for chromosome preparations from mouse eggs. Cytogenetics $\mathbf{5}$, $394-400$.

Tervit, H.R., Whittingham, D.G. \& Rowson, L.E.A. (1972) Successful culture in vitro of sheep and cattle ova. J. Reprod. Fert. 30, 493-497.

Wales, R.G. \& Whittingham, D.G. (1973) The metabolism of specifically labelled lactate and pyruvate by two-cell mouse embryos. J. Reprod. Fert. 33, 207-222.

Warburg, O. (1926) Uber den Stoffwechsel der Tumoren. Springer-Verlag, Berlin.

Whittingham, D.G. (1971) Culture of mouse ova. $J$ Reprod. Fert., Suppl. 14, 7-21.

Zawieja, D., Barber, B.J. \& Roman, R.J. (1984) Analysis of picogram quantities of protein in subnanoliter-size samples. Analyt. Biochem. 142, 182-188.

Received 6 June 1989 